Available online on 15.11.2020 at http://jddtonline.info
Open Access to Pharmaceutical and Medical Research
unrestricted non-commercial use, provided the original work is properly cited

Open 1 Access

Research Article

\title{
Structural and Electronic Factors Governing the Action of Anticonvulsants
}

\author{
John N Lisgarten ${ }^{1}$ and Rex A Palmer ${ }^{2}$ \\ ${ }^{1}$ School of Science, University of Greenwich (Medway Campus), Chatham Maritime, Kent ME4 4TB, UK \\ 2 Department of Crystallography, Biochemical Sciences, Birkbeck College, University of London, Malet Street, London WC1E 7HX, UK
}

\begin{abstract}
A selection of eighteen anticonvulsant drug molecules has been subjected to both geometrical analysis and atomic charge calculation to search for a link between structure and activity. A significant consequence of this study is the discovery of a fused 5,6,7 chemical ring system which suggests that these drugs may interact with a receptor site which is its topological complement. Molecular orbital calculations support the observation that anticonvulsant activity appears to be related to the net atomic charge on a specific carbon atom which is ce ntral to the fused ring system.
\end{abstract}

Keywords: Anticonvulsant, lamotrigine, epilepsy, charge calculation.

Article Info: Received 09 Sep 2020; $\quad$ Review Completed 21 Oct 2020; $\quad$ Accepted 29 Oct 2020; Available online 15 Nov 2020

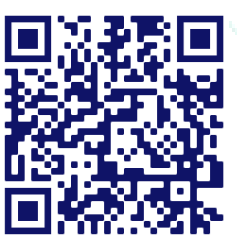

Cite this article as:

Lisgarten JN, Palmer RA, Structural and Electronic Factors Governing the Action of Anticonvulsants, Journal of Drug Delivery and Therapeutics. 2020; 10(6):67-73 http://dx.doi.org/10.22270/jddt.v10i6.4560

*Address for Correspondence:

John N Lisgarten, School of Science, University of Greenwich (Medway Campus), Chatham Maritime, Kent ME4 4TB, UK

\section{INTRODUCTION}

Over the years, many chemical compounds have been synthesised which have been shown to exhibit anticonvulsant activity. Some have eventually been incorporated into the range of proprietary drugs used for treating epilepsy, but unfortunately all have at least one undesirable characteristic which detracts from the constant use required by epilepsy sufferers. Somewhat surprisingly, the compounds cover a wide range of chemical types and it is this feature which creates difficulties in rational drug design. Anticonvulsant drugs have been studied for many years in the hope of elucidating the central nervous system (CNS) action. Consideration of structural features, including hydrogen bonding and charge distributions have been made in previous investigations into the basis of anticonvulsant activity.
These attempts to search for anticonvulsant structureactivity relationships via molecular structure parameters include: the studies of Andrews ${ }^{1}$ who employed the Extended Hückel Theory (EHT) of Hoffmann ${ }^{2}$ and the Complete Neglect of Differential Overlap (CNDO/2) of People and Segal 3,4 to calculate atomic charge distributions for a selection of anticonvulsant agents; the conformational studies of Camerman and Camerman 5,6,7; and the opposing studies of Jones and Woodbury ${ }^{8}$

\section{METHODS}

\section{Structure Analysis:}

In the present study two-dimensional projections of a selection of anticonvulsant drug molecules (Table1) were copied onto acetate sheets and the overlays examined for similar structural features. 


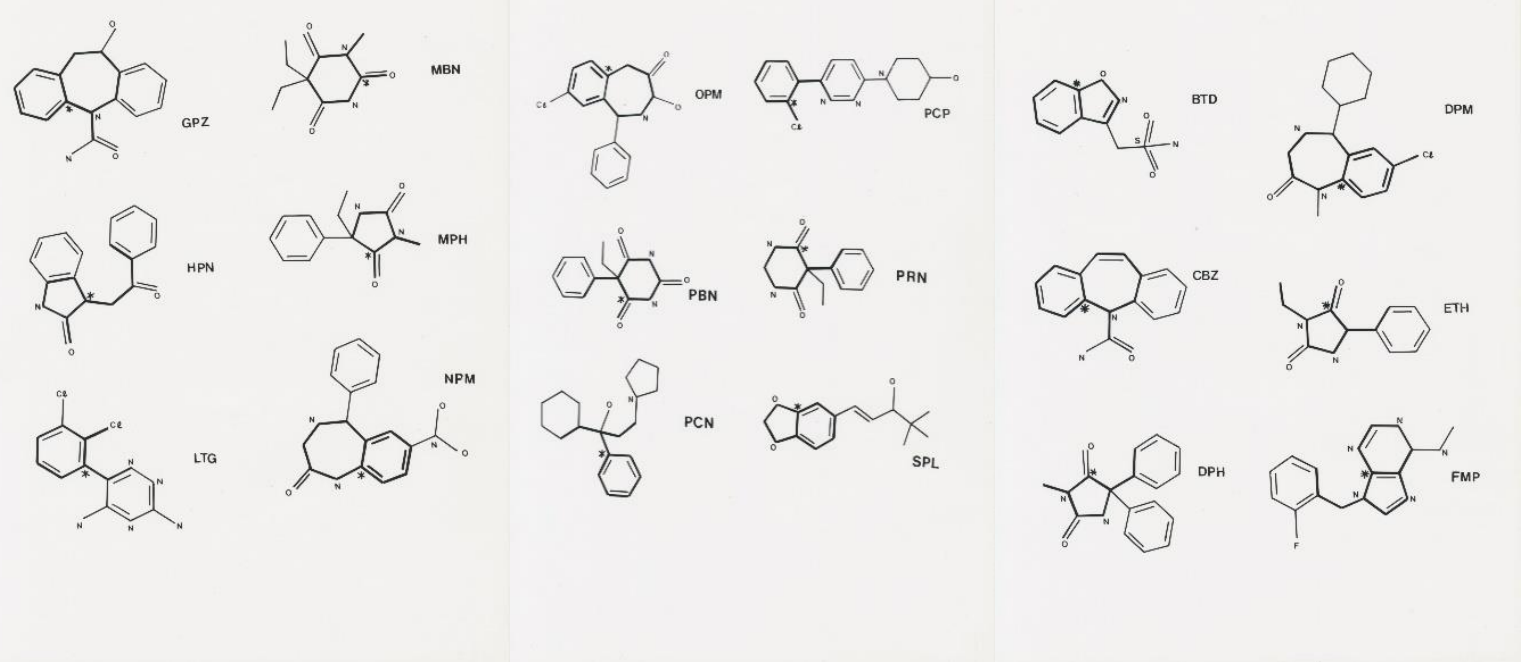

Table 1: Eighteen anticonvulsant drug molecules. The fragment contributing to the 5,6,7 ring system is indicated by bold lines. The "central" carbon atom is marked with an asterisk.

After several attempts to superpose the molecules in a variety of different orientations, an interesting pattern emerged when the structures were orientated about a central carbon atom which was often the connecting carbon of a phenyl ring. A fused 5,6,7 ring system was revealed (Figure 1), a substantial fragment from each drug molecule contributing to the overall system.

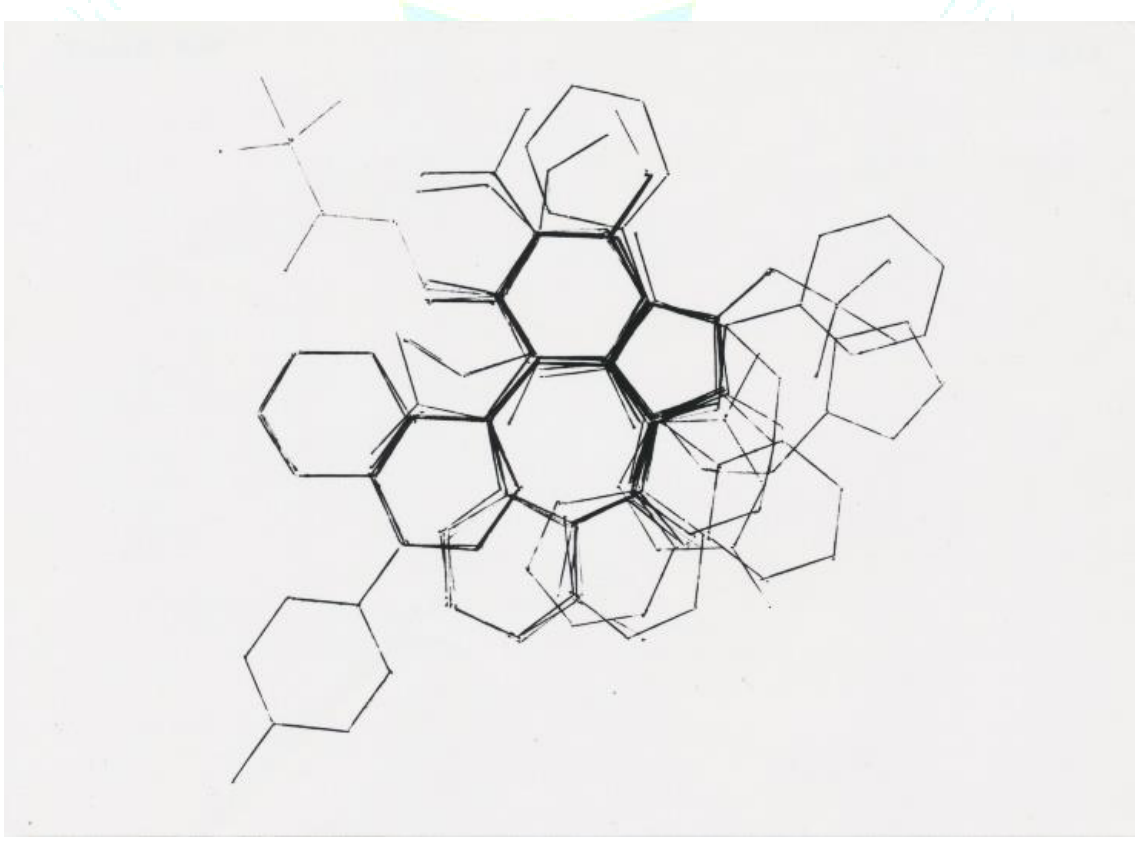

Figure 1: Overlay diagram composed from eighteen anticonvulsant drugs which exhibit MES activity

At this stage, it was decided to investigate the superposition of the molecular fragments which appeared to contribute to the system in three dimensions. The molecular fragments were obtained from the crystallographic coordinates of each molecule (Table 2), apart from the ethotoin (ETH) fragment which was model- built from the methoin (MPH) molecule dimensions. The molecular fragments were obtained from the crystallographic coordinates of each molecule (Table 2), apart from the ethotoin (ETH) fragment which was modelbuilt from the methoin (MPH) molecule. 
Table 2: Chemical details of the molecules used in this study

\begin{tabular}{|c|c|c|c|}
\hline Code & Compound & \multicolumn{2}{|c|}{ Reference } \\
\hline BTD & 3-sulphamoylmethyl-1,2-benzioxazole & \multicolumn{2}{|l|}{14} \\
\hline CBZ & 5-carbomoyl-5H-dibenz [b, f] azepine & \multicolumn{2}{|l|}{15} \\
\hline DPH & 5,5-diphenylhydantoin & \multicolumn{2}{|l|}{16} \\
\hline DPM & \multicolumn{2}{|c|}{ 7-chloro-1,3-dihydro-1-methyl-5-phenyl-2H-1, 4 benzodiazepine-2-one } & 17 \\
\hline ETH & 3-ethyl-5-phenylhydantoin & \multicolumn{2}{|l|}{ / } \\
\hline FMP & 9-(2-fluorobenzyl)-6-methylamino-9H-purine & \multicolumn{2}{|l|}{18} \\
\hline GPZ & 5-carbamoyl-10,11-dihydro-10-oxo-5H-dibenz [b, f] azepine & \multicolumn{2}{|l|}{19} \\
\hline HPN & 3-hydroxy-3-phenacyloxindole & \multicolumn{2}{|l|}{20} \\
\hline LTG & 3,5-diamino -6-(2,3-dichlorophenyl)-1,2,4- triazine & \multicolumn{2}{|l|}{11} \\
\hline MBN & 1-methyl-5,5-diethyl-barbituric acid & \multicolumn{2}{|l|}{21} \\
\hline MPH & 3-methyl-5-ethyl-5-phenylhydantoin & \multicolumn{2}{|l|}{22} \\
\hline NPM & 7-nitro-1,3-dihydro-5-phenyl-2H-1,4- benzodiazepine-2-one & \multicolumn{2}{|l|}{23} \\
\hline OPM & \multicolumn{2}{|c|}{ 7-chloro-1,3-dihydro-3-hydroxy-5-phenyl- 2H-1,4-benzodiazepin-2-one } & 24 \\
\hline PBN & 5-ethyl-5-phenyl-barbituric acid & \multicolumn{2}{|l|}{25} \\
\hline PCN & 1-cyclohexyl-1-phenyl-3-pyrolidinopropan-1-ol & \multicolumn{2}{|l|}{7} \\
\hline PCP & 3-(4-hydroxy-piperidinyl)-6-(2-chlorophenyl) pyridazine & \multicolumn{2}{|l|}{26} \\
\hline PRN & 5-ethyl-5-phenyl-hexahydro pyrimidine-4,6- dione & \multicolumn{2}{|l|}{27} \\
\hline SPL & 4,4-dimethyl-1-(3,4-methylenedioxyphenyl)-1- penten-3-ol & \multicolumn{2}{|l|}{28} \\
\hline
\end{tabular}

The superposition was obtained using the program QUANTA (Polygon User Manual, 1986) on a Silicon Graphics IRIS workstation running under the UNIX operating system. The results are presented in Figures 2 and 3. Figure 2 shows two views ((a) and (b)) of the fused 5,6,7 heterocyclic ring system built of eighteen molecular fragments from crystal structures, FMP being used as the base template. The atoms chosen for the superstition were those belonging to the 5and/or 6-membered rings of each fragment.

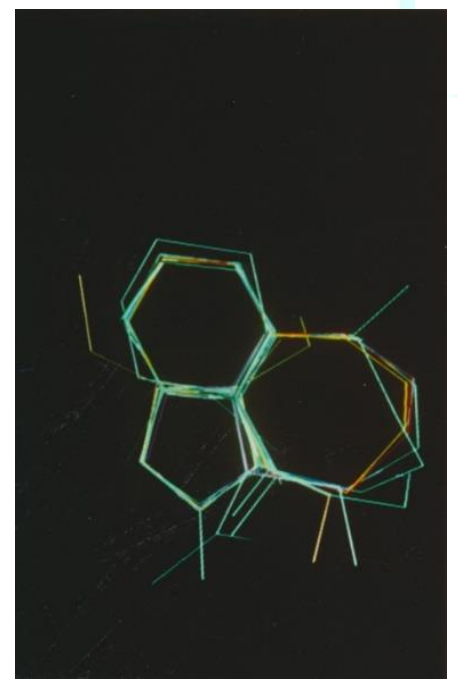

(a)

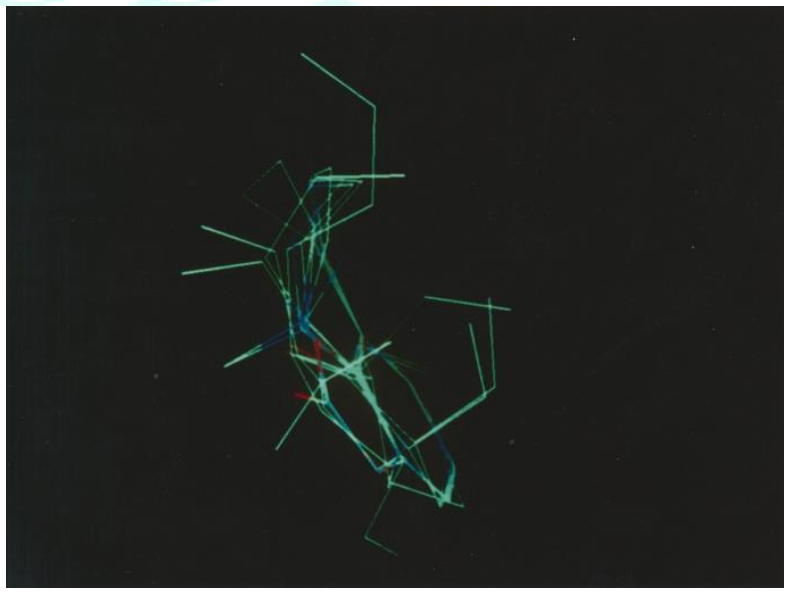

(b)

Figure 2(a): Plan view of the superposed eighteen fragments coloured according to atom type (Green-carbon, Blue-nitrogen, Red-oxygen).

Figure 2(b): As Figure 2(b) but elevation showing the concavity of the fused ring system. 
Figure 3(a) shows the superposition of eight structures solved in our laboratory.

These structures are colour- coded. Figure 3(b) shows all eighteen fragments superposed.

They are colour-coded but those already shown in Figure 3(a) are uniform green.

Table 3 gives the root mean square deviations between each fragment and the base template.

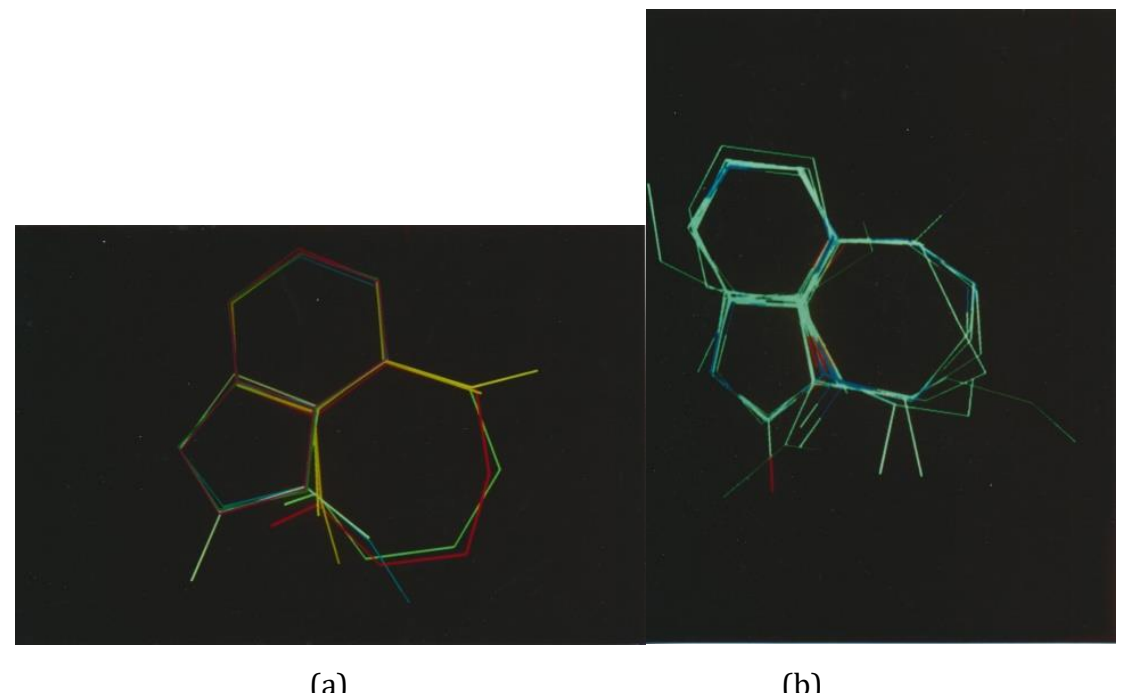

(a)

(b)

Figure 3(a): Superposed fragments of eight anticonvulsant structures solved in our laboratory. Colour coding: FMP-dark blue, BTD-purple, CBZ-light green, GPZ-red, LTG-yellow, MPH-white, PCP-orange, SPL-dark green.

Figure 3(b): All eighteen fragments superposed onto FMP.

\section{Charge Calculations:}

Molecular orbital calculations were performed on the eighteen drug molecules using the program MOPAC 9 which incorporated the MNDO semi-empirical Hamiltonian ${ }^{10}$ to determine the net atomic charge on the central carbon $\left(\mathrm{C}^{*}\right)$. It was found that the charge on this atom was positive in all cases (Table 4). In a second group of calculations, a series of analogues of the antiepileptic drug lamotrigine (3,5-diamino6(2,3-dichlorophenyl)-1,2,4-triazine) (LTG), were selected to investigate the relationship between the net atomic charge and activity. A consistent set of activity data (MES using

Table 3: Root mean square deviations

between each fragment and the base template.

\begin{tabular}{|ll|}
\hline Compound & RMS (̊) \\
BTD & 0.072 \\
CBZ & 0.068 \\
DPH & 0.094 \\
DPM & 0.068 \\
ETH & 0.091 \\
FMP & 0.000 \\
GPZ & 0.075 \\
HPN & 0.261 \\
LTG & 0.084 \\
MBN & 0.118 \\
MPH & 0.075 \\
NPM & 0.090 \\
OPM & 0.079 \\
PBN & 0.157 \\
PCN & 0.046 \\
PCP & 0.064 \\
PRN & 0.239 \\
SPL & 0.076 \\
\hline
\end{tabular}

mice) were provided by Wellcome Laboratories U.K. (Table 5).

The structures of the analogues were model - built from the crystallographic coordinates of LTG ${ }^{11}$ using the CHEM-X12 molecular modelling package on an Evans and Sutherland PS300 graphics device with a Vax 11/750 host computer. Molecular orbital calculations were performed on the modelbuilt drug molecules using the MOPAC program to determine the net atomic charge on each of the atoms. All calculations were run on a Vax 11/750 computer.

Table 4: Calculated charge on central ( $\mathrm{C}^{*}$ )

Carbon atoms of each molecule.

\begin{tabular}{|ll|}
\hline Compound & Charge on C*(electrons) \\
BTD & 0.08 \\
CBZ & 0.13 \\
DPH & 0.35 \\
DPM & 0.15 \\
ETH & 0.34 \\
FMP & 0.12 \\
GPZ & 0.16 \\
HPN & 0.13 \\
LTG & 0.10 \\
MBN & 0.37 \\
MPH & 0.35 \\
NPM & 0.18 \\
OPM & 0.14 \\
PBN & 0.37 \\
PCN & 0.00 \\
PCP & 0.01 \\
PRN & 0.36 \\
SPL & 0.03 \\
\hline
\end{tabular}


Table 5: MES activity data for LTG analogues

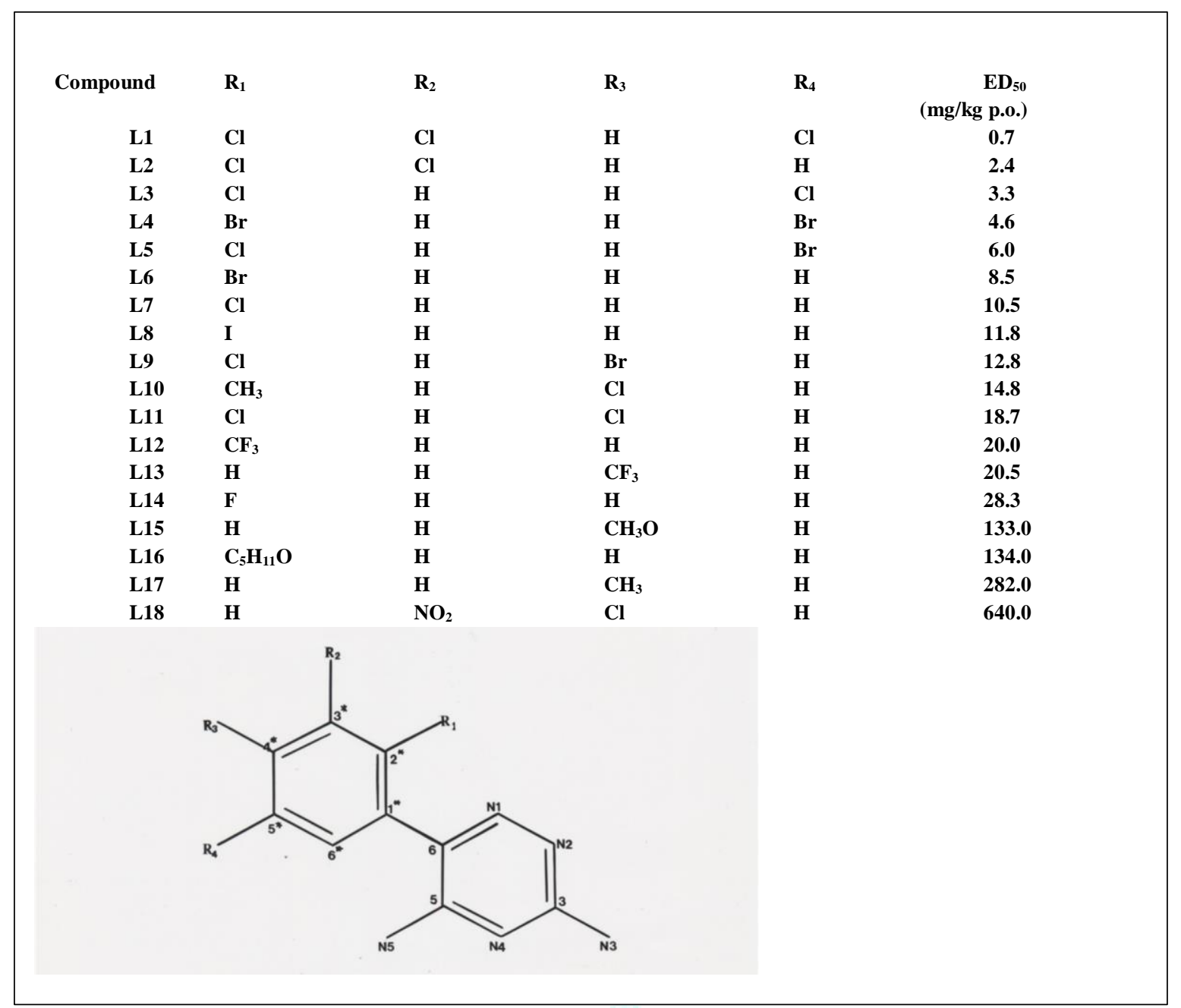

\section{RESULTS AND DISCUSSION}

The computer - aided superposition again displayed the 5,6,7- fused heterocyclic ring system. The fused ring system was in the same orientation except for GPZ (coloured red) (Figure 3b) where the 7-membered ring appears to be conformationally opposite to the general trend. However, deuterated high-temperature NMR studies (R. Lancaster, personal communications) indicates that the GPZ molecule in solution is in a state of continuous flipping between two conformations. This may explain the apparent discrepancy regarding this fragment because the crystallographic structure determination presents only one conformation. The elevation view (Figure $2 \mathrm{~b}$ ) shows the 5,6 ring sections of the system to be relatively rigid while the 7-membered component exhibits a degree of flexibility. Inspection of Figure 2 indicates a distinct clustering of electronegative atoms (nitrogen and oxygens, coloured blue and green) adjacent to the central carbon ( $\mathrm{C}^{*}$ ).

The charge calculations and subsequent correlation analysis performed on these atoms indicated that no linear relationship existed between the charges on the atoms and the anticonvulsant activity. However, the results indicate that the charge on the central carbon atom $\left(\mathrm{C}^{*}\right)$ was consistently positive although its magnitude is not a predictor of anticonvulsant activity. Correlation analysis was also performed on all atoms common to the LTG structure. As with the previous analysis, no correlations were found. However, it was noted that the charge on the phenyl carbon C (1) * (see Table 6) is positive for molecules of high activity and negative for those of low activity.

Taken together, the above observations suggest that these drugs may interact with a receptor binding site which reciprocates both topologically and electronically the 5,6,7 heterocyclic ring pattern derived in these studies. The positive charge on $\left(\mathrm{C}^{*}\right)$ presumably results from the electron - withdrawing nature of either adjacent electronegative atoms, or from larger moieties in distant regions of the molecule. Thus, the receptor binding site may be in the form of a shallow concave or convex surface with a centrally placed negative charge. Since it is known that many of these molecules are sodium channel blockers, it is possible that the central positive charge on the molecules is attracted to the same site as the sodium ion, blocking the channel instead of being transported through. It is of interest to note that a search of the literature has revealed a group of compounds synthesised by the Upjohn company having the fused 5,6,7 fused ring system ${ }^{13}$. Although these compounds have never been commercially available, it is suggested that further studies on these and similar compounds may provide a lead in the development of more reliable anticonvulsant drug. 
Table 6: Calculated charges on selected atoms of LTG analogues.

\begin{tabular}{|c|c|c|c|c|c|}
\hline \multirow[t]{2}{*}{ Compound } & \multirow[t]{2}{*}{$\tau$} & \multicolumn{3}{|c|}{ Calculated charge (electrons) } & \multirow[b]{2}{*}{$\mathrm{C}(6)$} \\
\hline & & $\mathrm{C}\left(1^{*}\right)$ & $\mathrm{C}(2 *)$ & $\mathrm{C}\left(6^{*}\right)$ & \\
\hline \multirow[t]{2}{*}{ L1 } & -96.2 & 0.02 & 0.03 & 0.01 & -0.16 \\
\hline & 92.8 & 0.02 & 0.04 & 0.00 & -0.16 \\
\hline \multirow[t]{2}{*}{ L2 } & -93.5 & 0.01 & 0.03 & -0.01 & -0.15 \\
\hline & 93.4 & 0.01 & 0.03 & -0.01 & -0.15 \\
\hline \multirow[t]{2}{*}{ L3 } & -91.3 & 0.01 & 0.04 & -0.02 & -0.15 \\
\hline & 91.7 & 0.01 & 0.03 & 0.00 & -0.16 \\
\hline \multirow[t]{2}{*}{ L4 } & -90.8 & 0.01 & 0.05 & -0.01 & -0.16 \\
\hline & 09.6 & 0.01 & 0.03 & 0.01 & -0.15 \\
\hline \multirow[t]{2}{*}{ L5 } & -95.4 & 0.02 & -0.06 & -0.01 & -0.15 \\
\hline & 91.5 & 0.02 & -0.06 & -0.01 & -0.15 \\
\hline \multirow[t]{2}{*}{ L6 } & -92.6 & 0.01 & -0.05 & -0.04 & -0.15 \\
\hline & 91.7 & 0.02 & -0.06 & -0.02 & -0.14 \\
\hline \multirow[t]{2}{*}{ L7 } & -95.1 & 0.00 & 0.02 & -0.02 & -0.13 \\
\hline & 92.1 & 0.00 & 0.02 & -0.02 & -0.14 \\
\hline \multirow[t]{2}{*}{ L8 } & -93.2 & 0.04 & -0.25 & -0.03 & -0.15 \\
\hline & 92.1 & 0.04 & -0.25 & -0.03 & -0.16 \\
\hline \multirow[t]{2}{*}{ L9 } & -93.8 & 0.02 & 0.01 & -0.02 & -0.15 \\
\hline & 91.5 & 0.02 & 0.01 & -0.02 & -0.15 \\
\hline \multirow[t]{2}{*}{ L10 } & -90.6 & 0.01 & -0.05 & -0.04 & -0.15 \\
\hline & 85.8 & 0.01 & -0.07 & -0.03 & -0.15 \\
\hline \multirow[t]{2}{*}{ L11 } & -94.5 & 0.02 & 0.02 & -0.02 & -0.15 \\
\hline & 92.1 & 0.02 & 0.02 & -0.02 & -0.16 \\
\hline \multirow[t]{2}{*}{ L12 } & -95.2 & 0.06 & -0.15 & -0.04 & -0.16 \\
\hline & 86.7 & 0.06 & -0.14 & -0.04 & -0.15 \\
\hline \multirow[t]{2}{*}{ L13 } & -95.6 & 0.03 & -0.04 & -0.05 & -0.16 \\
\hline & 85.7 & 0.03 & -0.04 & -0.04 & -0.16 \\
\hline \multirow[t]{2}{*}{ L14 } & -92.7 & -0.05 & 0.19 & -0.01 & -0.14 \\
\hline & 82.9 & -0.04 & 0.17 & 0.00 & -0.14 \\
\hline \multirow[t]{2}{*}{ L15 } & -92.7 & -0.03 & -0.01 & -0.03 & -0.14 \\
\hline & 87.0 & -0.06 & -0.01 & 0.01 & -0.13 \\
\hline \multirow[t]{2}{*}{ L16 } & -94.2 & -0.03 & -0.12 & -0.01 & -0.12 \\
\hline & 91.9 & -0.03 & -0.14 & -0.03 & -0.12 \\
\hline \multirow[t]{2}{*}{ L17 } & -95.0 & -0.02 & -0.03 & -0.04 & -0.14 \\
\hline & 88.6 & -0.02 & -0.04 & -0.03 & -0.13 \\
\hline \multirow[t]{2}{*}{ L18 } & -96.0 & -0.02 & 0.05 & 0.01 & -0.17 \\
\hline & 89.1 & -0.01 & 0.02 & 0.01 & -0.17 \\
\hline
\end{tabular}




\section{REFERENCES}

1 Andrews PR. Molecular Orbital Calculations on Anticonvulsant Drugs. J. Med.Chem. 1969; 10:761.

2 Hoffmann R. An Extended Hückel Theory 1 Hydrocarbons. J. Med. Chem. 1963; 39:1397-1492.

3. Pople JA, Santry DP and Segal GA. Approximate Self-consistent Molecular Orbital Theory 1. Invariant Procedures. J. Chem. Phys. 1965; 43:S129-135.

4. People JA and Segal GA. Approximate Self-Consistent Molecular Orbital Theory. 111. CNDO Results for AB2 and AB3 Systems. J. Chem. Phys.1966; 44:3289.

5. Camerman A and Camerman N. Stereochemical similarities in chemically different antiepileptic drugs. Adv. Neurol. 1980; 27:223-235.

6. Camerman A and Camerman N. On the Crystallography and Stereochemistry of Antiepileptic Drugs. Acta. Crystallogr. 1981; B37:1677-1679.

7. Camerman N and Camerman A. The Stereochemical Basis of Anticonvulsant Drug Action. Mol. Pharmacol. 1971; 7:406-421.

8. Jones GL and Woodbury M. Antiepileptic Drugs (Wood, Pendry and Pippenger, eds.) Raven N.Y. 1982.

9. Steward J. "MOPAC" Quantum Chemistry Program Exchange, Dept. Chem., University of Indiana, USA. 1986.

10. Dewar MJS and Thiel WJ. Ground states of molecules. The MNDO method. Approximations and parameters. 38. Am. Chem. Soc, 1977; 99:4899-4907.

11. Janes RW, Lisgarten JN and Palmer RA. Structure of lamotrigine methanol solvate 3,5 diamino-6-(2,3-dichlorophenyl)-1,2,4triazine methanol, a novel anticonvulsant drug. Acta. Crystallogr. 1989; C45:129-132.

12. Davies E K. CHEM-X, Chemical Design Ltd. Oxford.

13. Hester JB, Rudzie AD and Veldkamp W. Pyrrolo[3,2,1-jk] [1,4] benzodiazepines and pyrrolo[1,2,3-ef] [1,5] benzodiazepines which have central nervous system activity. J.Med. Chem. 1970; 15:827-835.

14. Lisgarten JN and Palmer RA. The Structure of (1,2-Benzisoxazol3-yl) methanesulfonamide: A Novel Antiepileptic Drug. Acta. Crystallogr. 1988; C44:2013-2016.

15. Lisgarten JN, Saldanha JW and Palmer RA. Crystal and molecular structure of 5-carbamyl-5H-dibenzo- [b, f] azepine J. Cryst. Spect. Res. 1989; 19:641-649.
16. Camerman A and Camerman N. The stereochemical basis of anticonvulsant drug action. I. The crystal and molecular structure of diphenylhydantoin, anoncentrosymmetric structure solved by symbolic addition. Acta. Crystallogr, 1971; B27:22052211.

17. Camerman A and Camerman N. Stereochemical basis of anticonvulsant drug action. II. Molecular structure of diazepam. J. Am. Chem. Soc. 1972; 94:268-272.

18. Lisgarten JN and Palmer RA. Structure of 9-(2-fluorobenzyl)-6methylamino-9H-purine hydrochloride, a novel anticonvulsant. Acta. Crystallogr. 1988; C44:654-657.

19. Lisgarten JN, Saldanha JW and Palmer RA. The structure of 10,11-dihydro10-hydroxy-5H-dibenz [b, f] azepine -5carboxamide, an anticonvulsant drug molecule. Acta. Crystallogr. 1989; C45:656-658.

20. Codding PW, Lee TA and Richardson J F. Cyheptamide and 3hydroxy-3-Phenacyloxindole structural similarity to diphenylhydantoin as the basis for anticonvulsant activity. J. Med. Chem. 1984; 27:649-654.

21. Wünderlich H. Structure of 1-methyl-5,5-diethylbarbituric acid. Acta. Crystallogr. 1973; B24:168-172.

22. Lisgarten $\mathrm{J} N$ and Palmer RA. The structure of methoin: an anticonvulsant drug. Acta. Crystallogr. 1980; B36:2345-2349.

23. Gilli G, Bertolasi V, Sacerdoti M and Borea P A. 7-Nitro-1,3dihydro-5-phenyl-2H-1,4-benzodiazepin-2-one (nitrazepam). Acta. Crystallogr. 1977; B33:2664-2667.

24. Gilli G, Bertolasi V, Sacerdoti M and Borea PA. The crystal and molecular structure of 7-chloro-1,3-dihydro-3-hydroxy-5phenyl-2H-1,4-benzodiazepin-2-one (oxazepam). Acta. Crystallogr. 1978; B34:2826-2829.

25. Williams P. Polymorphism of phenobarbitone: the crystal structure of 5-ethyl-5-phenylbarbituric acid monohydrate. Acta. Crystallogr. 1973; B27:1572-1579

26. Lisgarten JN and Palmer R A. Structure of 1- [6 - (2chlorophenyl)-3-piperidin-4-ol, an anticonvulsant drug. Acta. Crystallogr. 1989; C45:102-104.

27. Yeats DGR and Palmer R A. The crystal structure of primidone. Acta. Crystallogr. 1975; B31:1077-1082.

28. Lisgarten J N and Palmer R A. The structure of stiripentol:4,4dimethyl-1-(3,4-methylenedioxyphenyl)-1-pentene-3-ol- a novel antiepileptic drug. Acta Crystallogr. 1988; C44:1992-1994. 